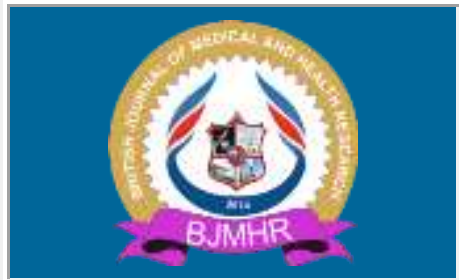

\title{
BJMHR
}

British Journal of Medical and Health Research Journal home page: www.bjmhr.com

\section{Cytological and Histological Studies on the Hepatotoxic Effects of Sorafenib (Nexavar) in Albino Rats}

Eman M. Abd-Ella1,2*, Abd-ElKarim M. Abdel Latif ${ }^{1}$

1 Zoology Department - Faculty of Science - Fayoum University - Fayoum - Egypt. 2 Biology Department - Faculty of Science and Art - Al-Baha Univeristy - Al-MandaqSaudi Arabia

\section{ABSTRACT}

Sorafenib (Nexavar) is an oral inhibitor of multi-kinase proteins approved in 2005 for treatment of metastatic advanced hepatocellular carcinoma. It causes many metabolic side effects, including diarrhea, hypertension, hand-foot skin reaction, and fatigue. This study aims to detect the histopathological, histochemical and DNA contents changes of the rat's liver under Nexavar treatment. The rats were divided into 3 groups. - Group 1: Served as control (rats were orally administrated with $\mathrm{ml}$ of normal saline for a month. - Group 2: Rats of this group were treated with the multikinase inhibitor Sorafenib $(60 \mathrm{mg} / \mathrm{kg}$ body weight/day) for 15 days by gavage. Group 3: Rats of this group were treated with the multikinase inhibitor Sorafenib $(60 \mathrm{mg} / \mathrm{kg}$ body weight/day) for 30 days by gavage. Animals were sacrificed and specimens from the liver were processed for histopathological, histochemical; by estimation of total carbohydrates and total protein contents; and cytological studies by estimation of DNA contents at the different stages of the cell cycle by the flow cytometer analysis. The results explained that in treated animals, there were histopathological and histochemical alterations, as a destruction of the normal hepatic architecture, swollen hepatocytes with vacuolar degenerated cytoplasm. Some hepatocytes showed mild to severe signs of injury such as swelling of their nuclei. Karyolysis of other hepatocytes are encountered. Severe reduction in the glycogen and proteins contents of the hepatocytes was observed by using PAS and bromophenol blue staining techniques. In addition, the results showed that Nexavar causes apoptosis by $15.41 \%$ and $13.72 \%$ in both groups 2 and 3, respectively. Liver genotoxicity induced by Nexavar for 15 and 30 days decreases the G1 cells constitute to $5.08 \%$ and $6.50 \%$ and increases the S-phase cells constitute to $19.17 \%$ and $20.28 \%$, respectively. Moreover, the G2 cells increases to $2.32 \%$ and 2.45 , about half of the last amount is aneuploidy cells. As a conclusion, Nexavar treatment showed mild to moderate hepatotoxic effects and induces many histological, histochemical and cytological changes causing liver damage.

Keywords: Nexavar, Hepatotoxicity, histopathology, PAS, Bromophenol blue, Flowcytometry.

*Corresponding Author Email: eman_abdella@yahoo.co.uk Received 18 March 2019, Accepted 23 March 2019

Please cite this article as: Abd-Ella EM et al., Cytological and Histological Studies on the Hepatotoxic Effects of Sorafenib (Nexavar) in Albino Rats. British Journal of Medical and Health Research 2019. 


\section{INTRODUCTION}

Systemic cancer therapy has evolved from the classic cytotoxic agents to now include newer classes of molecularly targeted therapy where the chemotherapy is an essential component in the treatment of cancer (1). Newer therapies target specific cancer molecules involved in regulating cancer cell growth and differentiation depending on that the Classic cytotoxic agents target rapidly proliferating cells by interfering with their cell division and growth. With the varying mechanisms of action, it is not surprising that the side effects of different anticancer agents and treatment modalities are diverse, affecting nearly every organ system where both systemic and localized therapies are known to have adverse effects on normal tissues (2).

According to Lovet, Sorafenib is a multikinase inhibitor that targets platelet-derived growth factor and vascular endothelial growth factor (3). Keating and Ma added that Sorafenib exhibits its effect by the way of inhibiting the multiple cell surface and intracellular kinases. These kinases are responsible for angiogenesis, apoptosis and tumorgenesis (4 and 5). Hepatic and gastrointestinal toxicities are a more common complication of cytotoxic cancer chemotherapy. Where the cytotoxic drugs do not differentiate between normal cells and cancer cells (6 and 7).

The aim of the present work was to investigate the structural changes associated with the cancer therapy drug; Sorafenib (Nexavar); in the liver tissues using cytological, histological and histochemical studies.

\section{MATERIALS AND METHOD}

\section{Chemicals:}

Nexavar, $200 \mathrm{mg}$, is a kind gift obtained from the medical union pharmaceutical drug company (MUP), Egypt, imported from Germany. Patients were started on Nexavar on a twice-daily schedule (200 mg bid or $400 \mathrm{mg}$ bid depending on their status). Adverse events were reported and graded according to the National Cancer Institute Common Terminology Criteria (NCICTCAE) on days 15 and 30 after treatment initiation (8).

\section{Animals:}

Adult male albino rats Rattus albus (8 weeks old) weighing 120-130 g, were selected from the animal house of National Research Center, Giza, Egypt. The animals were housed under controlled environment conditions ( $12 \mathrm{~h}$ light/dark cycle) at a temperature of $25^{\circ} \mathrm{C}+10^{\circ} \mathrm{C}$ and humidity of $60 \%+5 \%$ and fed standard diet and water Ad libitum for the experimental period.

\section{Experimental protocol:}

The experimental rats were randomly divided into 3 groups of 12 animals each as follows:

- Group 1: served as control where the rats were orally administrated with one ml of normal saline for a month. 
- Group 2: Rats of this group were treated with $60 \mathrm{mg} / \mathrm{kg}$ body weight/day of Nexavar (9) for 15 days by gavage.

- Group 3: Rats of this group were treated with $60 \mathrm{mg} / \mathrm{kg}$ body weight/day of Nexavar for 30 days by gavage.

\section{Examinations:}

At the end of experimentation, the liver of each animal was obtained and fixed in buffered neutral formalin $10 \%$ solution for $24 \mathrm{hrs}$, dehydrated through ascending series of alcohols, cleared in xylene and embedded in paraffin wax. $5 \mu \mathrm{m}$ thickness paraffin sections were obtained. For histopathological studies and according to Lillie and Fulmer some liver sections from the different groups were deparaffinized and stained with Ehrlich.s hematoxylin and counterstained with eosin (10). For histochemical studies some other liver sections were deparaffinized and prepared for the detection of total carbohydrates (1, 2 glycol group) (11) and some other sections were stained with bromophenol blue method to demonstrate total proteins (12).

For cytological study; Flow-cytometrical analysis was used. DNA data were obtained from cell suspensions derived from the same paraffin blocks. Samples were analyzed on a flow cytometer system (Facscan, Becton Dickinson). Set to collect 10,000 cells. Normal paraffin embedded tissues of the normal liver were used as external controls to demonstrate diploid DNA (13).

\section{RESULTS AND DISCUSSION}

\section{Histopathological observations}

Histopathological observations of H\&E stained liver sections of control rats showed that liver exhibited normal architectures and consists of hepatic lobules, each is made up of radiating strands of hepatocytes around a central vein. The hepatic strands are separated by thin wall blood sinusoids. The polyhedral hepatocytes exhibit granular cytoplasm and embodying prominent centrally located nuclei-kupffer cells are found in the blood sinusoids (Fig. 1A) Microscopic examination of liver sections taken from rats orally administrated with Nexavar (60 mg/kg body wt./day) for 15 days, showed destruction of the normal hepatic architecture with disorganized and disrupted hepatic strands. Also, swollen hepatocytes with vacuolar cytoplasm were observed. Some hepatocytes showed slight signs of liver injury such as swelling of their nuclei and karyolysis of other hepatocytes nuclei (Fig. 1B, C \& D). Other areas of the liver sections revealed complete degenerated hepatocytes and highly vacuolated hepatocytes with collapsed and pyknotic nuclei surrounded by rare cytoplasm. Fibroblast like cells were also identified especially very near to the blood vessels. Dilated blood sinusoids 

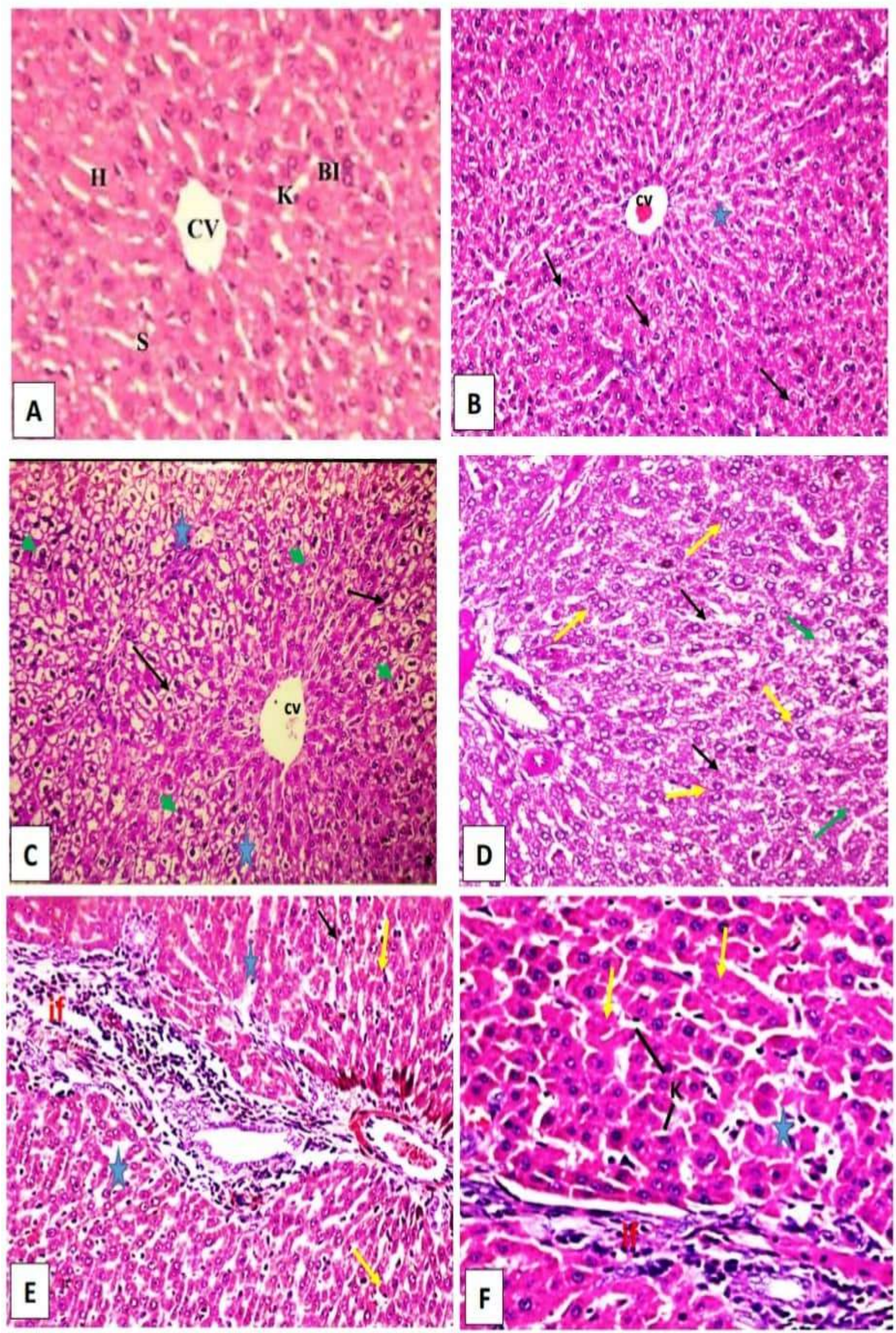

Figure 1. A photomicrograph of liver sections of control (A) and treated rats with Nexavar (60 $\mathbf{m g} / \mathbf{k g}$ body weight/day) for 15 days (B-F) showing: A- Hepatic strands $(\mathrm{H})$ which consist of hepatic cells, each cell exhibits eosinophilic cytoplasm and centrally located neucleus and some cells are binucleated (BI). The blood sinusoids (s) are lined with endothelial cells. The Kupffer cells (K) and the 
central vein $(\mathrm{CV})$ are shown. (H\&E - X, 400). B- Loss of liver architecture, sever hepatocytes karyolitic, polymorphic and cytoplasmic degeneration $(*)$ are shown. Congested central vein $(\mathrm{CV})$ and hepatocytes' degeneration are found (arrow). (H\&E - X, 200). C- Moderately differentiated hepatic degenerated cells shows nuclear atrophy and necrosis (arrow). In addition there is loss of liver architecture $(*)$ and dilated central vein $(\mathrm{CV})$. Pyknotic nuclei are present (head of arrow) $(\mathbf{H} \& \mathbf{E}-\mathbf{X}$, 200). D- Loss in the liver architecture with hepatocyte degeneration (arrow), several binucleated hepatocytes (yellow arrow) in addition many karyolitic nuclei (green arrow) are shown. (H\&E $-\mathbf{X}$, 200). E- Inflammatory cells infiltration (if), sinusoid dilatation (*) and cells proliferation with pyknotic nucleus (arrow) are present. Karyolitic hepatocytes with diffuse of Kupffer cells proliferation in between (yellow arrow) are found. (H\&E - X, 200). F- Loss of liver architecture, and degenerated hepatocytes $(*)$ are shown. Karyolitic hepatocytes (yellow arrow), pyknotic Kupffer cells (K) and inflammatory cells infiltration (if) are found. $(\mathbf{H} \& \mathbf{E}-\mathbf{X}, \mathbf{4 0 0})$.

were present with slight erosion of their endothelial cells together with inflammatory cell infiltration (Fig. 1 E \& F). Also, hypertrophied probably activated kupffer cells were observed very close to the disintegrated hepatocytes.

Examination of liver sections taken from rats treated with Nexavar $(60 \mathrm{mg} / \mathrm{kg}$ body wt./day) for 30 days showed severe damages in the liver architecture and different signs of alterations were observed in the hepatic tissue similar to those observed after 15 days exposure. In addition, necrotic masses probably granulose like structure were identified in many places of the liver and were represented by ruptured and fragmented hepatocytes, cell debris and enormous densely basophilic pyknotic nuclei and numerous lymphocytes (Fig. 2 A, B and C). This necrotic mass was probably dissolved latter and almost no residual tissue architecture was preserved in the insulted region. At the periphery of the necrotic mass phagocytic cells were sometimes demonstrated. The inflammatory leucocytes were also shown around the branches of the portal vein, probably infiltrate from their walls invading the hepatic tissue. The bile ductile was enlarged with expanded lumens and proliferation of their epithelial cells (Fig. 2 D).

Other degenerated areas of the liver sections after 30 days exposure showed highly distorted, disorganized and destructed hepatocytes. These areas displayed an enhanced degree of deterioration and many hepatocytes showed high degree of dissolution (Fig.2 C, D \&E). Hepatocytes of these areas showed highly vacuolated cytoplasm with vesiculated nuclei (Fig.2 D\&E). Also, many pyknotic nuclei were encountered. Activated and hypertrophied probably kupffer cells were observed at these areas of degeneration. Binucleated degenerated hepatocytes with highly vacuolated cytoplasm were also encountered in the liver tissue. The cytoplasmic vacuoles may represent certain degree of hydropic or fatty degeneration and cloudy swelling. 

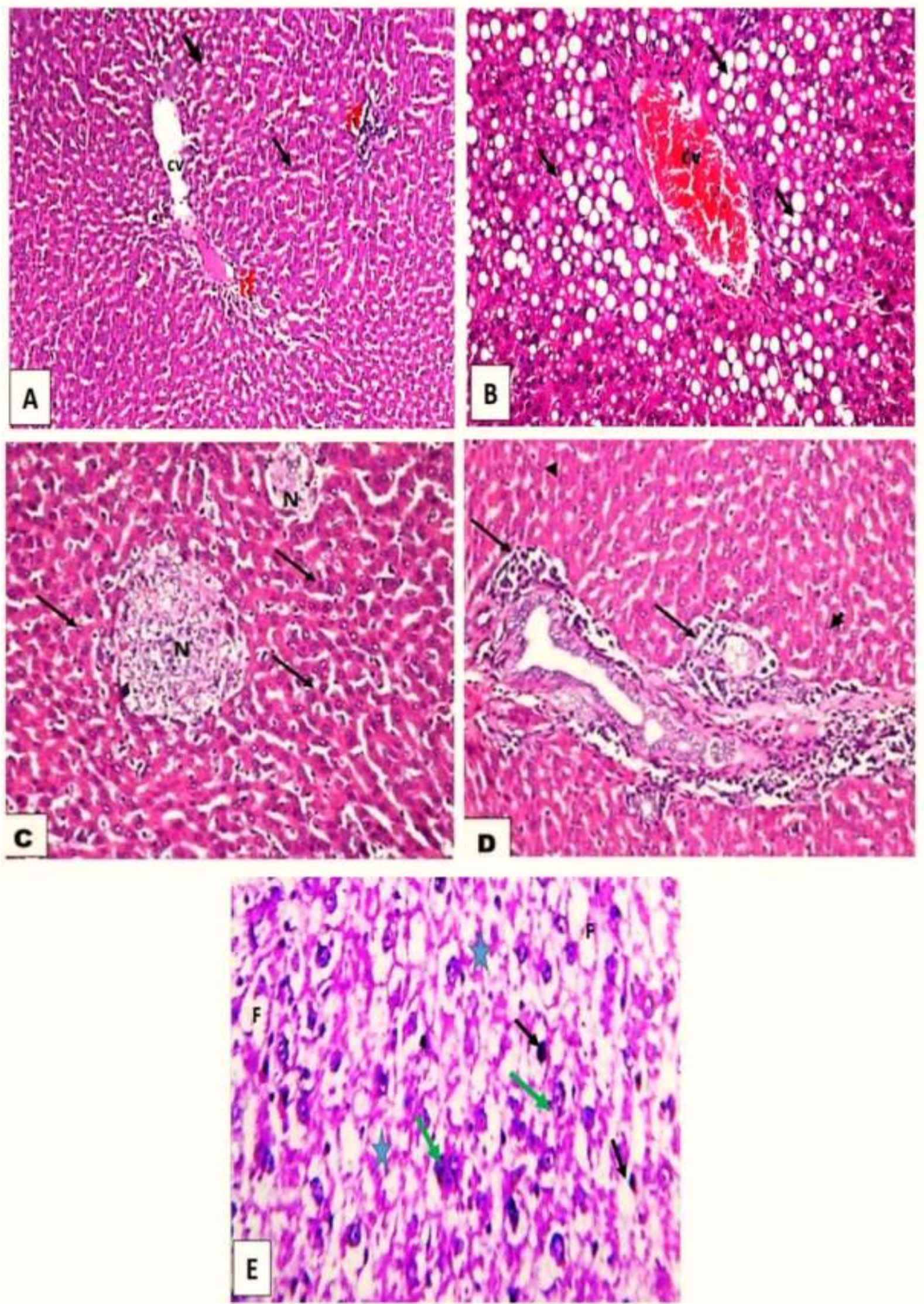

Figure 2. A photomicrograph of liver sections of rats treated with Nexavar (60 mg/kg body weight/day) for 30 days showing: A- Loss in the liver architecture with focal areas of inflammatory cells infiltration (if), dilated and congested central vein (CV) and liver cells degeneration with pyknotic nuclei (arrow) are found. 
(H\&E - X, 100). B- Dilated and congested central vein (CV) and liver cells degeneration with cytoplasmic fatty vaculation (arrow) are found. (H\&E $-\mathbf{X}, \mathbf{2 0 0})$ C- Loss in the liver architecture with focal areas of necrosis (N) and liver cells degeneration with pyknotic nuclei (arrow). (H\&E $-\mathbf{X}, \mathbf{2 0 0})$. D- Cells inoculation displaying hypertrophy of liver cells, necrotic area with mononuclear cells infiltration near central vein (arrow) and deeply stained pyknotic nuclei (head arrows). (H\&E - X, 200). E- Cytoplasmic fatty vaculation (f) and hepatocyte degeneration (*), in addition many karyolitic nuclei (green arrow) and pyknotic Kupffer cells (arrow) are observed. (H\&E - X, 400).

\section{Histochemical observations}

Examination of liver sections of control rats stained with PAS method showed a strong PAS positive particles of different sizes in the hepatocytes (Fig.3 A1). However in case of rats treated with Nexavar for 15 days, the hepatocytes exhibited moderate and weak PAS-reactivity and a tendency towards polysaccharides diminution (Fig.3 A2). After 30 days exposure of Nexavar, a severe depletion of polysaccharides were observed in the hepatocytes (Fig.3 A3).

A strong to deep bromophenol blue reaction was observed in the hepatocytes of control rats denoting a high protein content of such cells treated with Nexavar for 15 days revealed remarkable decrease of protein content of the hepatocytes around the central vein, while other hepatocytes showed strong bromophenol blue reaction for protein. A great loss of protein content was observed in both the hepatocytes cytoplasm and nuclei of the rats treated for 30 days with Nexavar (Figs. 3 B1, 2 $\& 3)$.

\section{Cytological observations}

\section{Flowcytometric analysis (DNA contents in liver cells measurement)}

In the liver cells, as most dividing cells, the DNA content immediately after division, represents the diploid chromosomal complement $(2 \mathrm{~N})$; this increases during the DNA synthetic phase $(\mathrm{S})$. The flow-cytometer technique measures the amount of DNA per cell by quantization the intensity of the fluorescence emitted by a DNA-bound dye flow past a high-intensity laser beam. From the present data, a histogram can be constructed showing the frequency with which the DNA content appear in the cell population.

Figure 4 (A) show a histogram for the control liver cells suspension. The abscissa represents the DNA value, while the ordinate represent the number of cells examined. The mean percentage value of the G1-cells constitutes $10.44 \%$, the S-phase cells constitute $3.81 \%$ and the $\mathrm{G} 2$ cells $0.41 \%$ (Table 1 ).

In addition, figure 4 (B and C) shows that Nexavar causes apoptosis by $15.41 \%$ and $13.72 \%$ in both groups 2 and 3, respectively. Liver genotoxicity induced by Nexavar for 15 and 30 days 


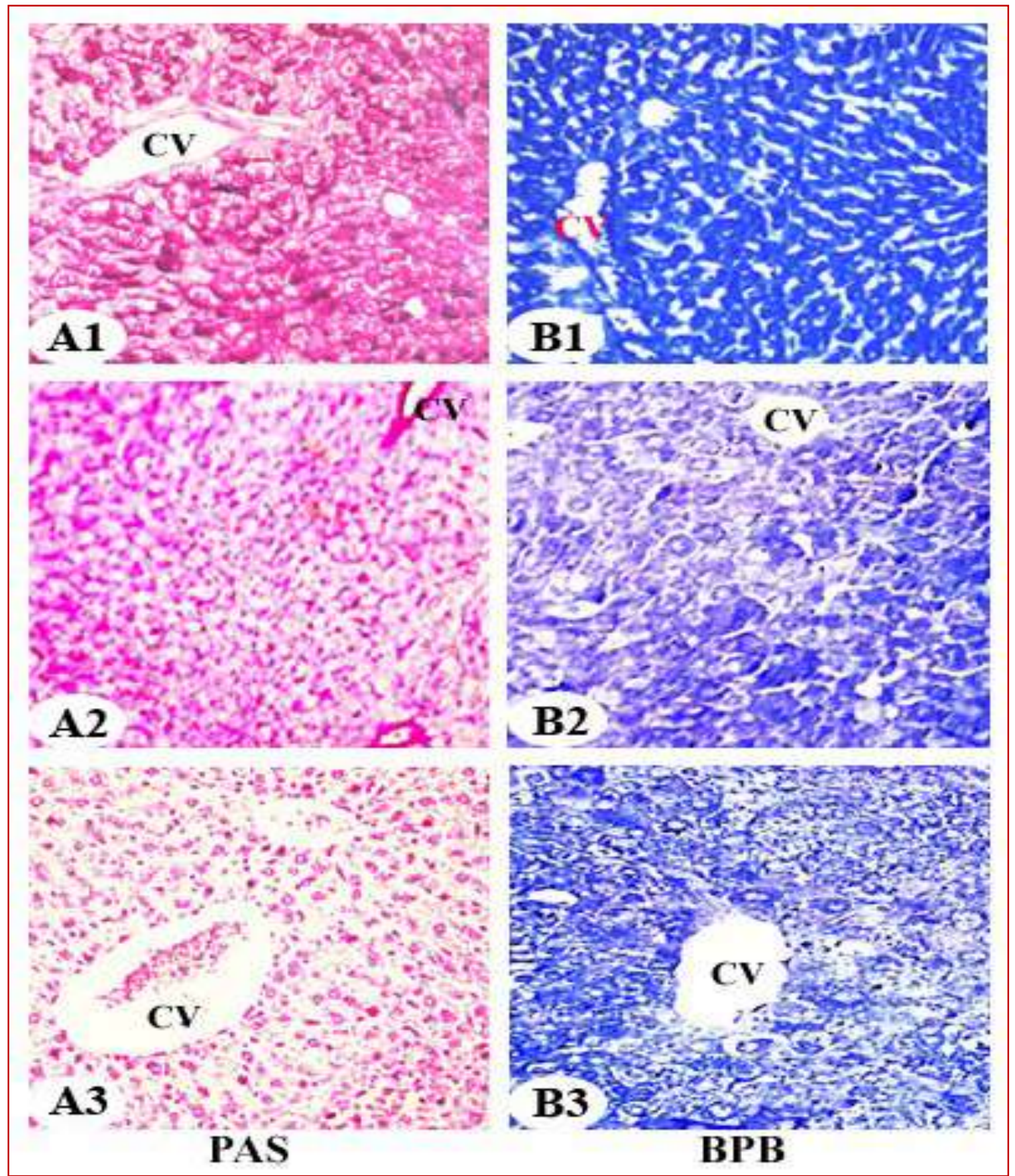

Figure 3. Photomicrograph of liver sections stained for polysaccarides by PAS (A1, 2\&3) and for total protein by Bromophenol Blue (B1, 2 \&3) showing: A1. Control liver section with strong +ve PAS reaction in the cytoplasm of hepatocytes. A2. Treated liver section with Nexavar $(60 \mathrm{mg} / \mathrm{kg}$ body weight/day) for 15 days showing decreased PAS reactivity in the cytoplasm of hepatocytes. A3. Treated liver section with Nexavar $(60 \mathrm{mg} / \mathrm{kg}$ body weight/day) for 30 days showing marked decreased PAS reactivity in the cytoplasm of many hepatocytes. (PAS - X, 200). B1. Photomicrograph of liver section stained for total protein by bromophenol blue (BPB) showing dense blue reaction in control rats indicating high protein content. B2. Liver sections of treated rats with Nexavar $(60 \mathrm{mg} / \mathrm{kg}$ body weight/day) for 15 days showing decreased stainablity of BPB +ve materials. B3. Strong decreased in bromophenol blue +ve materials were observed in hepatocytes of rats treated with Nexavar $(60 \mathrm{mg} / \mathrm{kg}$ body weight/day) for 30 days. (Bromophenol blue - X, 200). 
decreases the G1 cells constitute to $5.08 \%$ and $6.50 \%$ and increases the S-phase cells constitute to $19.17 \%$ and $20.28 \%$ respectively. Moreover, the G2 cells increases to $2.32 \%$ and 2.45 , about half of the last amount is aneuploidy cells (table 1).
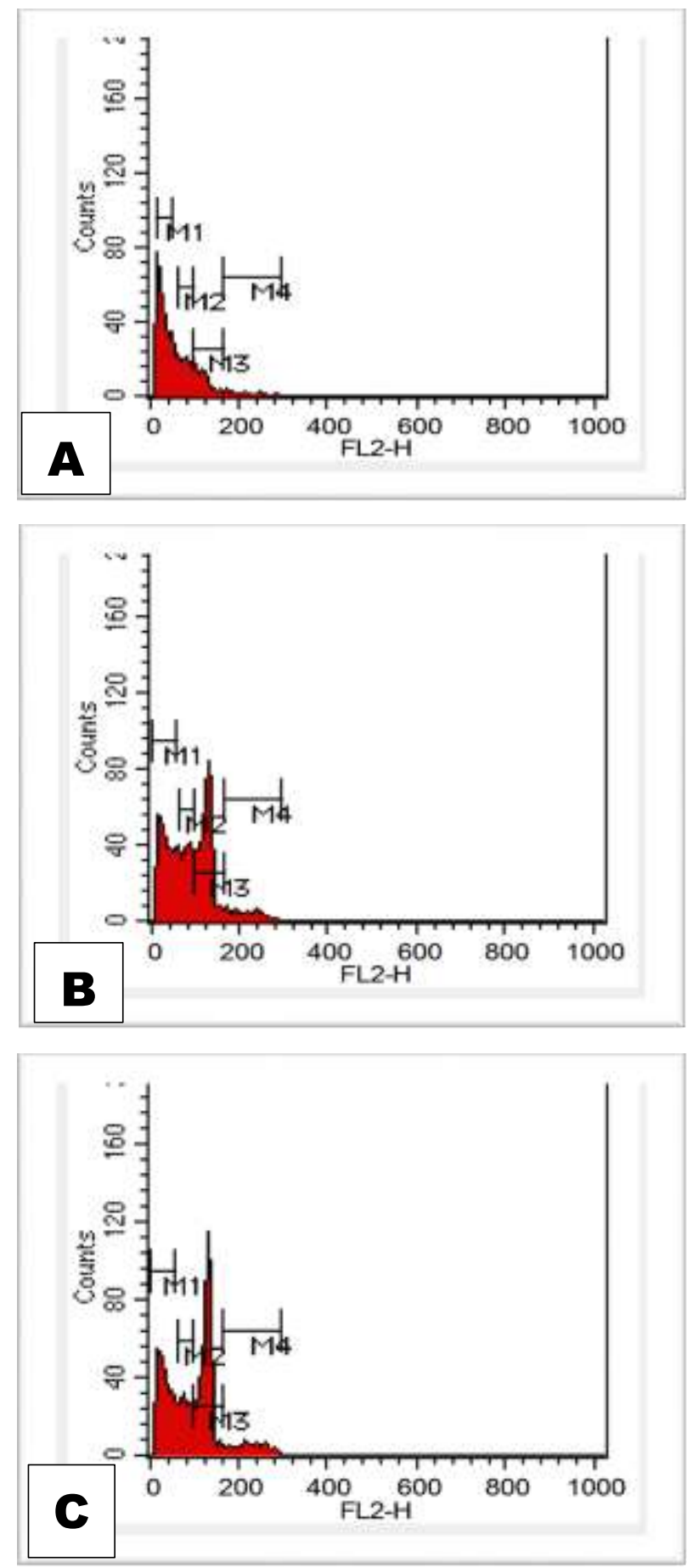

Figure 4. Flow cytometrical histograms of different groups: A: liver section of control rat. B: liver section obtained from a rat treated with Nexavar $(60 \mathrm{mg} / \mathrm{kg}$ body weight/day) for 15 days by gavage. C: liver sections obtained from a rat treated with Nexavar $(60 \mathrm{mg} / \mathrm{kg}$ body weight/day) for 30 days by gavage.

Where, M1= apoptosis, M2= G0//1, M3=S\%, M4= G2/M 
Table (1): The apoptosis percentage and the cell cycle phases in different experimental groups.

\begin{tabular}{llll}
\hline Groups & $\begin{array}{l}\text { (Group 1) } \\
\text { Control }\end{array}$ & $\begin{array}{l}\text { (Group 2) } \\
\text { Nexavar for 15 days }\end{array}$ & $\begin{array}{l}\text { (Group 3) } \\
\text { Nexavar for 30 days }\end{array}$ \\
\cline { 1 - 3 } \% Total & & 15.41 & 13.72 \\
\cline { 1 - 2 } Apoptosis\% & 12.92 & 5.08 & 6.50 \\
G0/1 phase \% & 10.44 & 19.17 & 20.28 \\
S phase \% & 3.81 & 2.32 & 2.45 \\
G2/M phase \% & 0.41 & & \\
\hline
\end{tabular}

\section{DISSCUSION}

The multikinase inhibitor Nexavar was recently approved for the treatment of hepatic cellular carcinoma in the United States and the European Union, and may be used in an increasing number of countries (14). Severe side effects may limit or even exclude therapy with Nexavar (15 and 16). On the other hand, tumor independent benefits cannot be excluded in Nexavartreated patients (17 and 18). In this concern, the present results suggested that liver tissues may be at a higher risk for Nexavar-induced liver damage. This study indicated that Nexavar induced marked histopathological, histochemical and cytological alterations in the liver tissues of male albino rats, including inflammatory infiltration, hyperplasia, periportal fibrosis, marked disruption of hepatic cords and dilated blood sinusoids. In addition, many degenerated hepatocytes, enlargement of hepatocyte cytoplasm and karyomegaly with many vacuolated and pyknotic nuclei indicating apoptosis.

The morphology of the cytoplasmic vacuoles observed in the present study was indicated that they may be represent fat droplets which had dissolved via dehydration during the tissue processing. Salem and Wahba revealed that these vacuoles represent hydropic degeneration in the affected cells (19 and 20). In this respect, Venditti considered the cytoplasmic vaculation in the animal cells as a result of the break-down of lipoprotein complexes in the affected cells (21). Both lipolytic (fatty) or hydropic degeneration were reported by ElShershaby who studying the effect of the antifungal drug Itraconazole on the liver of pregnant rats and their fetuses (22).

The liver is known to accumulate significant amounts of Nexavar, second to the kidney, thus hepatotoxicity can be associated with Nexavar treatment (23). Clinical evidence of Nexavarinduced liver injury has been demonstrated by elevated activities of serum enzymes and bilirubin levels (24).

In the same context, Ting, reported that the presence of both focal inflammation and portal inflammation, focal congestion and hemorrhage, focal hepatocyte apoptosis and lytic necrosis in the rats administered a single dose Sorafenib (10 mg/kg, p.o.) (25). 
In 2014, Roberto demonstrated that hepatotoxicity is a relatively common adverse event occurring in $23-40 \%$ of patients with $\mathrm{HCC}$ who are treated with tyrosine kinase inhibitors (TKIs) such as Nexavar, and it is manifested by increased AST and ALT levels (26). The histopathological alterations characteristic of TKIs-induced hepatotoxicity such as sinusoidal congestion, hepatocyte necrosis, inflammation and hepatocyte loss around the hepatic venue in a patient with gastrointestinal stromal tumors (27 and 28). Similar histopathological alterations (lobular hepatitis with mononuclear cell infiltration and hepatocyte necrosis) characteristic of Sorafenib-induced hepatotoxicity have been reported in many case reports (16, 29 and 30).

The mechanism by which Sorafenib induces hepatotoxicity remains unclear. A review of the literature of liver biopsies revealed centri-lobular hepatocellular necrosis and lympho-plasma cellular and granulocytic infiltration of the portal tracts with significant eosinophilia, consistent with hyper allergic drug reactions (25).

According to Farber, the cell death results from naturally occurring apoptosis (physiological apoptosis) or from irreparable cell injury (pathological apoptosis) (31). Apoptosis is a common feature of hepatotoxicity induced by many chemicals; it may precede necrosis, as in the hepatotoxicity induced by thioacetamide (32), or it may occur concurrently with necrosis as in hepatotoxicity associated with acetaminophen (33). Hobeebu reported that necrosis may be due to the direct attack of the cell membrane by the toxicant or interacting with some specific components of metabolic pathway (34). In 1999 Leek demonstrated that necrosis may be due to the decrease in blood supply to an area of the tissue and to the focal macrophages infiltration (35).

Nexavar as a multikinase drug is thought to kill cells primarily by forming DNA adducts, causing G2 arrest in the cell cycle, triggering apoptosis (36). This findings were in agreement with our cytological results showed previously in table 1.

A number of studies indicated that enzyme activation of Nexavar begins with the drug conversion to a free radical via one-electron reduction, and such a reaction is catalyzed by several enzymes, including P-450 reductase (37). In the present study, hepatic damage as mentioned above was accomplished by inflammatory cells forming granulomatous lesions and periportal fibrosis after Nexavar administration. According to Reynaert and Friedman, Nexavar has been shown to induce accumulation of inflammatory cells, and this may associated with increased activities of tissue aminotransferases (ALT \& AST), LDH and ALP (38 and 39).

Lysosomal enzymes discharged from disintegrated cells have a key role in the induction of necrotic changes. Where lysosomes are responsible for regulated degradation of the autophagic vacuoles. In apoptosis, lysosomes degrade the contents of phagocytic vacuoles derived from 
engulfed apoptotic blebs. Telbisz mentioned that activation of autophagy is frequently observed in different types of pathological tissue degeneration (40).

The present study showed that treated rats with Nexavar caused a depletion of the total carbohydrate contents and marked decrease in protein contents in the cytoplasm of the hepatocytes. Depletion of glycogen that was observed in the present study was most probably consequent to hydropic and fatty degeneration manifested in this work, or may be due to the damaging effects of Nexavar on the cytoplasmic organelles and the associated enzymes, where Popp and Cattley reported that the decrease in mucopolysaccharides content in tissues may be due to disturbed role of Golgi apparatus which is responsible for synthesis of polysaccharides (41). Andreassen added that mitochondrial dysfunction can lead to energy deficiency, ionic imbalance, and elevated reactive oxygen species (ROS) and oxidative damage (42). According to Nelson the disturbances in the total carbohydrate contents were suggested to be achieved through modifying the activities of the enzymes of glycolytic pathway, tricarboxylic acid cycle (TCA), glycogenesis and the oxidation of phosphorylation (43).

The histochemical changes observed in the present work showed clear reduction in the protein contents that may reflects a disturbance in protein synthesis. Also, Sivaprasada found that the reduction of protein contents may be attributed partially to the hyperactivity of hydrolytic enzymes or may be due to the biological reactive intermediates; which are electron-deficient compounds (electrophiles) that bind to cellular electron-rich compounds (44). Such as proteins and lipids reactive intermediates bind covalently to critical cellular macromolecules and interfere with normal biologic activity (45). This may referred to the consequence of the damage produced in the rough endoplasmic reticulum and Golgi apparatus and detachment of ribosomes by diclofenac sodium as reported by Elewa (46).

\section{CONCLUSION:}

The present study showed that Nexavar treatment induces liver damage that was performed by histological, histochemical and cytological changes. These changes may be due to the effects of reactive oxygen species (ROS) which could damage the cellular elements.

\section{REFERENCES}

1. Robinson, S. M.; Scott, J.; Manas, D. M. and White, S. A. (2013). The assessment and management of chemotherapy associated liver injury, hepatic surgery. Prof. Hesham Abdeldayem (ed) ISBN: 978-953-51-0965-5. INTECH, doi: 10.5772/53915.

2. King, P. D. and Perry, M.C. (2001). Hepatotoxicity of chemotherapy. Oncologist, 6:162-176.

3. Lovet, J. M.; Ricci, S.; Mazzaferro, V. et al. (2008). Sorafenib in advanced hepatocellular carcinoma. North England J Medical, 359(4): 378-390. 
4. Keating, G. M. (2017). Sorafenib: A Review in Hepatocellular Carcinoma. Target Oncology, 12:243-53.

5. Ma, R.; Chen, J.; Liang, Y.; Lin, S.; Zhu, L.; Liang, X.; et al. (2017). Sorafenib: A potential therapeutic drug for hepatic fibrosis and its outcomes. Biomedical Pharmacotherapy, 88:459-68.

6. Hernandez-Gea, V.; Toffanin, S.; Friedman, S. L. and Llovet, J. M. (2013). Role of the microenvironment in the pathogenesis and treatment of hepatocellular carcinoma. Gastroenterology, 144:512-527.

7. Luedde, T. and Schwabe, R. F. (2011). NF-kappaB in the liver-linking injury, fibrosis and hepatocellular carcinoma. Nat Rev Gastroenterology Hepatology, 8:108-118.

8. National Cancer Institute (2006). Common Terminology Criteria for Adverse Events v3.0.

9. Martin Hennenberg, Jonel Trebicka, Zaki Kohistani, Christian Stark, Hans-Dieter Nischalke1, Benjamin Kra“mer, Christian Ko“ rner, Sabine Klein, Michaela Granzow, Hans-Peter Fischer, Jo“ rg Heller and Tilman Sauerbruch (2010). Hepatic and HSCspecific Sorafenib effects in rats with established secondary biliary cirrhosis. labinvest.148; 241-251. Doi: 10.1038

10. Lillie, R. D. and Fulmer, H. M. (1976). Histopathological technique and practical histochemistry. $4^{\text {th }}$ Edn., New York, Mc Graw Hill.

11. Hotchkiss, R. D. (1948). A microchemical reaction resulting in the staining of Polysaccharides structures in fixed tissue preparations. Archives of Biochemistry, 16: 131-44.

12. Maize, D.; Brewer, P. A. and Affert, M. (1953). The cytochemical staining and measurements of protein with mercuric bromophenol blue. Bid. Bull., 104: 57-67.

13. Headley, D.W.; Friedlander, M. L.; Taylor, I. W.; Rugg; G. C. and Musgrove; E. A. (1983). Method for analysis of cellular DNA content of paraffin-embedded pathological material using flow-cytometry. Hematol. Oncology Clinical North American; 12: 943 - 61.

14. Cheng, A.L.; Kang Y.K.; Chen Z., et al. (2009). Efficacy and safety of Sorafenib in patients in the Asia-Pacific region with advanced hepatocellular carcinoma: a phase III randomized, double-blind, placebo-controlled trial. Lancet Oncology, 10:25-34.

15. Schramm, C.; Schuch, G.; Lohse, A.W. (2008). Sorafenib-induced liver failure. American J Gastroenterology, 103:2162-2163. 
16. Llanos, L.; Bellot, P.; Zapater, P.; et al. (2009). Acute hepatitis in a patient with cirrhosis and hepatocellular carcinoma treated with Sorafenib. American J Gastroenterology, 104:257-258.

17. Pinter, M.; Sieghart, W.; Graziadei, I.; et al. (2009). Sorafenib in unrespectable hepatocellular carcinoma from mild to advanced stage liver cirrhosis. Oncologist. $14: 70-76$.

18. Yau, T.; Chan, P.; Ng, K. K.; Chok, S. H.; Cheung, T. T.; Fan, S. T.; \& Poon, R. T. (2009). Phase 2 open-label study of single-agent sorafenib in treating advanced hepatocellular carcinoma in a hepatitis B-endemic Asian population. Cancer, 115 (2), 428-436.

19. Salem, F. M., lottfi, M.; Naunou, A.; Aref, H. and Mansoury, H. (1985). Hazardous effect of application of the herbicide (gesaprim) on balady rabbit. Vet. Med. J., 33(2): $239-251$.

20. Wahba, S.R. (1987). Histochemical and histological studies on the effect of amphetamine on the liver of rat. Egypt. J. Histol., 9(1): 101 - 107.

21. Venditti, P.; De Rosa, R. and Di Meo, S. (2004). Effect of cold-induced hyperthyroidism on $\mathrm{H} 2 \mathrm{O} 2$ production and susceptibility to stress condition of rat livermitochondria. Free Rolic. Biol. Med., 36: 348 - 358.

22. El-shershaby, A. M.; Dakrory, A. I.; El-Dakdoky, M. H.; Ibrahim, J. and Kassem, F. (2015). Biomonitoring of the genotoxic and hepatotoxic effects and oxidative stress potentials of Itraconazole in pregnant rats. Birth defects research part (B):1 - 10 .

23. Zhou, Q.; Hennenberg, M.; Trebicka, J.; Jochem, K.; Leifeld, L.; Biecker, E.; ... \& Heller, J. (2006). Intrahepatic upregulation of RhoA and Rho-kinase signalling contributes to increased hepatic vascular resistance in rats with secondary biliary cirrhosis. Gut, 55(9), 1296-1305.

24. Shah, V. (2009). Therapy for portal hypertension: what is our pipeline? Hepatology; 49:4-5.

25. Ting, C. T.; Cheng, Y. Y.; \& Tsai, T. H. (2017). Herb-drug interaction between the traditional hepatoprotective formulation and sorafenib on hepatotoxicity, histopathology and pharmacokinetics in rats. Molecules, 22(7), 1034.

26. Roberto, I.; Antonella, P.; Giuseppe, P.; Matteo, S.; Patrizia, T.; Angelina, D.B.; Silvia, M. and Enrico, C. (2014). Incidence and relative risk of hepatic toxicity in patients treated with anti-angiogenic tyrosine kinase inhibitors for malignancy. Br. J. Clin. Pharmacol., 77, 929-938. 
27. Tonyali, O.; Coskun, U.; Yildiz, R.; Karakan, T.; Demirci, U.; Akyurek, N.; Benekli, M. and Buyukberber, S. (2010). Imatinib mesylate-induced acute liver failure in a patient with gastrointestinal stromal tumors. Med. Oncol., 27, 768-773.

28. Klempner, S.J.; Choueiri, T.K.; Yee, E.; Doyle, L.A.; Schuppan, D.; Atkins, M.B. (2012). Severe pazopanib-induced hepatotoxicity: Clinical and histologic course in two patients. J. Clin. Oncol., 30, e264-e268.

29. Herden, U. and Fischer, L. (2010). Sorafenib-induced severe acute hepatitis in a stable liver transplant recipient. Transplantation, 90, 98-99.

30. 30- Fairfax, B.P.; Pratap, S.; Roberts, I.S.D.; Collier, J.; Kaplan, R.; Meade, A.M.; Ritchie, A.W.; Eisen, T.; Macaulay, V.M.; Protheroe, A. (2012). Fatal case of sorafenib-associated idiosyncratic hepatotoxicity in the adjuvant treatment of a patient with renal cell carcinoma. BMC Cancer, 12, 590-594.

31. Farber, E. (1994). Programmed cell death: Necrosis versus apoptosis. Mod Pathology, 7:605-609.

32. Ledda-Columbano, G. M., Coni, P., Curto, M.; Giacomini, L.; Faa, G.; Oliverio, S.; Piacentini, M.; Columbano, A. (1991). Induction of two different modes of cell death, apoptosis and necrosis, in rat liver after a single dose of thioacetamide. Am J Pathol., 139:1099-1109.

33. Knight, T.R.; Fariss, M.W.; Farhood, A.; Jaeschke, H. (2003). Role of lipid peroxidation as a mechanism of liver injury after acetaminophen overdose in mice. Toxicol Sci., 76:229-36.

34. Hobeebu, S. S. J. and Klaassen, C.D. (1998). Cadmium induced apoptosis in mouse liver. Toxical. Appl. Pharmacol., 149: 203 - 209.

35. Leek, R.; Lander, R.; Harris, A. and Lewis, C. (1999). Necrosis correlates with high vascular density and focal macrophages infiltration. Cancer, 79: $991-995$.

36. Kishimoto, S.; Miyazawa, K.; Terakawa, Y.; Ashikari, H.; Ohtani, A.; Fukushima, S.; Takeuchi, Y. (2000). Cytotoxicity of cis-[((1R, 2R)-1, 2-cyclohexanediamine-N, N') bis (myristato)]-platinum (II) suspended in Lipiodol in a newly established cisplatinresistant rat hepatoma cell line. Jpn J Cancer Res., 91:1326-32.

37. Trebicka J., Hennenberg M., Laleman W., et al. (2007). Atorvastatin lowers in portal pressure in cirrhotic rats by inhibition of RhoA/Rho-kinase and activation of endothelial nitric oxide synthase. Hepatology, 46:242-253.

38. Reynaert, H.; Thompson, M. G.; Thomas, T., et al. (2002). Hepatic stellate cells: role in microcirculation and pathophysiology of portal hypertension. Gut; 50:571-581. 
39. Friedman, S. L. (2008). Mechanisms of hepatic fibrogenesis. Gastroenterology, 134:1655-1669.

40. Telbisz, A.; Kovacs, A. L. and Somosy, Z. (2002). Influence of X-ray on the autophagic - lysosomal system in rat pancreatic acini. Micron, 33 (2): 143-151.

41. Popp, J. A. and Cattely, R. C. (1991). Hepatobiliary System. In: Handbook of Toxicology and Pathology. Academic press, inc. London 14, pp.279.87. Prasad.

42. Andreassen, O. A.; Ferrante, R. J.; Klivenyi P., et al. (2000). Paratial deficiency of managanese superoxide dismutase exacerbates a transgenic mouse model of amyotrophic lateral sclerosis. Ann. Neruol., 47: 447-455.

43. Nelson, D. L.; Lehninger, A. L., \& Cox, M. M. (2008). Lehninger principles of biochemistry. Macmillan.

44. Sivaprasada, K.; Sombasiva, K. R. and Ramana, K. V. (1983). Effect of parathion on tissue ionic changes fish channa punctatus Geobios. Jodhpur, 10:60-62.

45. Goldstein, R. S. and Schellmann, R. G. (1995). Toxic responses of the kidney. In: casarett and Doull's Toxicology. The Basic Science of Poisons, ed., Klaassen CD, $5^{\text {th }}$ ed., pp 417- 442, McGraw-Hill companies Inc., New York, NY.

46. Elewa, F. H., Gabry, M. S. and Ibrahim, M. A. (1999). Ultrastructural changes produced by diclofenac sodium in the liver and duodenal epithelial cell of the guinea pig. Egypt. J. Zool., 33: 133-165. 


BJMHR is
- Peer reviewed
- Monthly
- Rapid publication
editor@bjmhr.com

